\title{
Analisis Efektivitas dan Kontribusi Pajak Hotel terhadap Pendapatan Asli Daerah (PAD) Kota Medan
}

\author{
Deasy Arisandy Aruan ${ }^{1}$ \\ Dianty Putri Purba ${ }^{2}$ \\ Fakultas Ekonomi \\ Fakultas Ekonomi \\ Universitas Prima Indonesia, Indonesia Universitas Prima Indonesia, Indonesia
}

\begin{abstract}
Surel : deasy.aruan@gmail.com
ABSTRAK

Tujuan penelitian adalah mengetahui efektivitas dan kontribusi Pajak Hotel terhadap Pendapatan Asli Daerah (PAD) Kota Medan. Sumber data adalah data sekunder berupa target dan realisasi Pajak Hotel dan realisasi Pendapatan Asli Daerah (PAD) Kota Medan tahun 2014 sampai tahun 2018. Teknik analisa data yang digunakan adalah menggunakan analisis deskriptif. Cara menganalisis data untuk mengetahui tingkat efektivitas adalah dengan membandingkan nilai realisasi dengan target pajak hotel yang telah ditetapkan Pemerintah Daerah Kota Medan. Dan untuk mengetahui cara menganalisis kontribusi Pajak Hotel terhadap Pendapatan Asli Daerah (PAD) adalah dengan membandingkan nilai realisasi Pajak Hotel dengan Pendapatan Asli Daerah (PAD). Hasil penelitian di tahun 2014-2018, efektivitas dan kontribusi cenderung fluktuatif setiap tahunnya. Nilai efektivitas pajak hotel bernilai 93-114\% dan berada dalam kriteria sangat efektif kecuali di tahun 2015 memasuki kriteria efektif. Sedangkan untuk kontribusi bernilai 5-7\%, sehingga berada dalam kriteria sangat kurang kontribusi pajak hotel dalam meningkatkan Pendapatan Asli Daerah (PAD) Kota Medan.
\end{abstract}

Kata Kunci: Pajak Hotel; Pendapatan Asli Daerah.

\section{Analysis of Effectiveness and Contribution Hotel Taxes to Regional Revenue of Medan City}

\section{ABSTRACT}

The purpose of this research is to find out how the effectiveness and contribution of hotel taxes in increasing the source of regional revenue. Sources of data used in this study are secondary data, there's the form of targets and realization of hotel tax revenue and realization of regional revenue (PAD) Medan City from 2014 to 2018. The data analysis technique used in this study is to use descriptive analysis. To determine the level of effectiveness is to compare the hotel tax realization value with the hotel tax target that has been set by the Regional Government of Medan City. And to find out how to analyze the contribution of hotel tax to Regional Revenue (PAD) is to compare the value of hotel tax realization with the realization of regional revenue (PAD) in Medan City. The research result states that in 2014-2018, the effectiveness and contribution of hotel tax tends to fluctuate every year. The value of hotel tax effectiveness is in the value of $93-114 \%$ and is in the very effective criteria, except in 2015 entering the effective criteria. Meanwhile, the contribution is worth $5-7 \%$, so that it is in the very poor criteria in increasing the regional revenue (PAD) of Medan City.

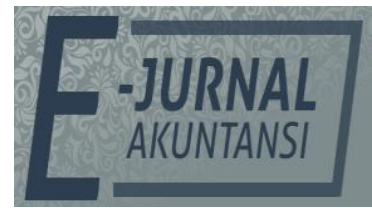

e-ISSN 2302-8556

Vol. 31 No. 3

Denpasar, Maret 2021

Hal. 704-712

DOI:

10.24843/EJA.2021.v31.i03.p14

PENGUTIPAN:

Aruan, D.A. \& Purba, D.P. (2021). Analisis Efektivitas dan Kontribusi Pajak Hotel terhadap Pendapatan Asli Daerah (PAD) Kota Medan. E-Jurnal Akuntansi, 31(3), 704-712

RIWAYAT ARTIKEL: Artikel Masuk: 12 November 2020 Artikel Diterima: 25 Maret 2020

Keywords: $\quad$ Hotel Tax; Regional Revenue (PAD).

Artikel dapat diakses : https://ojs.unud.ac.id/index.php/Akuntansi/index 


\section{PENDAHULUAN}

Pendapatan Asli Daerah (PAD) adalah pendapatan yang diperoleh daerah yang dipungut berdasarkan peraturan daerah sesuai dengan peraturan perundangundangan (Undang-Undang Nomor 33 Tahun 2004). Pendapatan Asli Daerah (PAD) memberikan wewenang kepada pemerintah daerah untuk mewujudkan desentralisasi dimana semakin besar nilai Pendapatan Asli Daerah (PAD), maka sebuah daerah mampu melakukan desentralisasi fiskal. Salah satu upaya dalam meningkatkan Pendapatan Asli Daerah (PAD) adalah meningkatkan efektivitas pemungutan pajak dan retribusi yang dilakukan dengan cara mengoptimalkan potensi yang ada dan terus menggali sumber pendapatan baru yang potensinya bagus, sehingga dapat dipungut pajak dan retribusinya (Octovido et al, 2014). Namun, jika suatu daerah memiliki sumber daya yang kurang potensial, maka kebijakan otonominya di daerah tersebut kurang menguntungkan (Norregard, 2013). Menurut Zhouhaier dalam (Taras \& Artini, 2017) otonomi daerah yang diberikan kepada pemerintah daerah menjadi iklim yang baik terhadap pertumbuhan ekonomi di berbagai daerah.

Sumber Pendapatan Asli Daerah (PAD) terdiri dari pajak daerah, retribusi daerah dan hasil perusahaan milik daerah dan hasil pengelolaan kekayaan daerah yang dipisahkan. Salah satu pajak daerah yang potensinya semakin berkembang sejalan dengan adanya trend staycation adalah pajak hotel. Trend staycation yang memakai konsep liburan dengan memanfaatkan hotel di dalam kota. Sejak tahun 2016, trend ini mulai popular di Indonesia. Buat keluarga yang ingin berlibur melepas penat tanpa menempuh jarak jauh, staycation 2-3 hari di hotel yang dekat dengan domisili adalah pilihan yang tepat. Namun, bagi para milenial, staycation 1 hari dimanfaatkan untuk mendokumentasikan foto atau video demi posting di sosial media. Pada tahun 2018, Pajak Hotel di kota Medan mengalami kenaikan siginifikan dimana realisasi pajak hotel 119,6 milyar dari yang telah ditargetkan Pemerintah Daerah sebesar 117 milyar (Bangun, 2019). Namun, pada tahun 2019, dalam pembahasan Laporan Pertanggungjawaban (LPj), pajak hotel dan pajak restoran dinilai tidak maksimal. Terdapat temuan BPK bahwa dari 502 hotel selaku wajib pajak, hanya sebanyak 370 hotel yang melaporkan pajaknya. Begitu juga dengan pajak restoran dari 400 lebih yang terdaftar sebagai wajib pajak, , hanya 200 restoran lebih yang melaporkan (Naibaho, 2019). Adanya perbedaan besar pemungutan pajak hotel di tahun 2018 dan 2019 menunjukkan adanya potensi pajak hotel yang belum digali secara maksimal. Dengan demikian pajak hotel di Kota Medan sebenarnya memiliki potensi yang besar dibanding dengan penerimaan pajak hotel 2018, dilihat dari minat staycation masyarakat yang kini semakin berkembang dari tahun ke tahun.

Beberapa penelitian telah dilakukan untuk peningkatan Pendapatan Asli Daerah Kabupaten/Kota adalah sebagai berikut:

Pendapatan Asli Daerah Kota Batu oleh Octovido et al (2014) menganalisa efektivitas dan kontribusi pajak daerah terhadap Pendapatan Asli Daerah di tahun 2009-2013. Efektivitas pajak daerah di tahun 2010 merupakan yang terendah karena penetapan target yang kurang realistis sehingga target tidak tercapai. Sedangkan, kontribusi Pajak daerah terhadap Pendapatan Asli Daerah sangat baik, karena selama 4 tahun terakhir tingkat kontribusinya diatas 50\%. 
Pendapatan Asli Daerah Kota Deli Serdang oleh Abdullah \& Puspita, (2016) menganalisa kontribusi pajak hotel terhadap Pendapatan Asli Daerah tahun 2011-2015, Hasil penelitian menunjukkan kontribusi pajak hotel di tahun 2011-2013 mengalami penurunan karena adanya kenaikan target pajak hotel yang tidak sebanding dengan kondisi penerimaan sebenarnya.

Pendapatan Asli Daerah Kabupaten Tana Toraja oleh (Tonapa et al., 2017) menganalisa kontribusi dan efektivitas pajak hotel terhadap Pendapatan Asli Daerah di tahun 2011-2015. Hasil penelitian menunjukkan bahwa kontribusi pajak hotel terhadap PAD masih kurang meskipun sistem pemungutan pajak daerah sudah mencapai tingkat $100 \%$ dan efektif. Sehingga, diharapkan Pemerintah Daerah Kabupaten Tana Toraja dapat menggali potensi yang ada, meningkatkan pengawasan dan memberikan sanksi administrasi kepada wajib pajak yang melakukan pelanggaran supaya Pendapatan Asli Daerah Kabupaten Tana Toraja dapat meningkat.

Pendapatan Asli Daerah Kabupaten Enrekang oleh Achsyariana, (2017) yang menganalisii kontribusi Wisata Alam Gunung Nona terhadap Pendapatan Asli Daerah Kabupaten Enrekang tahun 2013-2017. Hasil penelitian menunjukkan kontribusi diberikan oleh UMKM wisata alam Gunung Nona terhadap (PAD) Kabupaten Enrekang di kawasan wisata alam Gunung Nona dalam kurun waktu 5 tahun belum maksimal. Berdasarkan uraian, penulis merasa tertarik untuk meneliti permasalahan pajak hotel di Kota Medan dengan judul "Analisis Efektifitas dan Kontribusi Pajak Hotel terhadap Pendapatan Asli Daerah Kota Medan"

Menurut Saksono, (1984), efektivitas adalah seberapa besar tingkat kelekatan di antara keluaran (output) yang dicapai dengan keluaran yang diharapkan dari jumlah masukan (input) di dalam sebuah perusahaan atau seseorang. Jadi, dapat disimpulkan bahwa efektivitas adalah suatu kondisi yang menunjukkan tingkat keberhasilan atau tingkat pencapaian suatu tujuan yang dapat diukur dengan kualitas, kuantitas, serta juga waktu yang sesuai dengan yang sudah direncanakan sebelumnya. Berdasarkan Kepmendagri No.690.900.327 tahun 1996 tentang Interprestasi Kriteria Efektivitas, ukuran dalam mengukur kriteria efektivitas adalah sebagai berikut:

Tabel 1. Kriteria Efektivitas

\begin{tabular}{ll}
\hline Tingkat \% Efektivitas & Kriteria Efektivitas \\
\hline$\geq 100 \%$ & Sangat Efektif \\
$90 \%-100 \%$ & Efektif \\
$80 \%-90 \%$ & Cukup Efektif \\
$60 \%-80 \%$ & Kurang Efektif \\
$\leq 60 \%$ & Tidak Efektif \\
\hline
\end{tabular}

Sumber: Kepmendagri No.690.900.327 tahun 1996

Menurut (Dani, 2006: 264) Kontribusi diartikan sebagai uang sumbangan atau sokongan. Analisis kontribusi Pajak Hotel suatu analisis yang digunakan untuk mengetahui seberapa besar kontribusi yang dapat disumbangkan dari penerimaan pajak hotel terhadap pendapatan asli daerah untuk mengetahui seberapa besar kontribusi yang dapat disumbangkan dari Pajak Hotel terhadap Pendapatan Asli Daerah. Berdasarkan Tim Litbang Depdagri Fisipol UGM 
tahun 1991, cara untuk menginterprestasikan kontribusi pajak hotel adalah sebagai berikut.

Tabel 2. Kriteria Kontribusi

\begin{tabular}{ll}
\hline Tingkat \% Kontribusi & Kriteria Kontribusi \\
\hline$\geq 50 \%$ & Sangat Baik \\
$40,10 \%-50 \%$ & Baik \\
$30,10 \%-40 \%$ & Sedang \\
$20,10 \%-30 \%$ & Cukup \\
$10,10 \%-20 \%$ & Kurang \\
$0 \%-10 \%$ & Sangat Kurang \\
\hline
\end{tabular}

Sumber: Tim Litbang Depdagri Fisipol UGM (1991)

\section{METODE PENELITIAN}

Jenis penelitian yang dilakukan adalah studi kasus. Menurut (Sugiyono, 2016:17), penelitian dengan metode studi kasus adalah dimana peneliti melakukan eksplorasi secara mendalam terhadap program, kejadian, proses, aktivitas, terhadap satu atau lebih orang. Suatu kasus terikat oleh waktu dan aktivitas dan peneliti melakukan pengumpulan data secara mendetail dengan menggunakan berbagai prosedur pengumpulan data dan dalam waktu yang berkesinambungan.

Jenis data yang digunakan dalam penelitian ini adalah sebagai berikut: Data Kuantitatif yang berupa laporan dan berbentuk angka-angka, yaitu berupa target dan realisasi penerimaan Pajak Hotel dan realisasi Pendapatan Asli Daerah (PAD) Kota Medan tahun 2014 sampai dengan 2018. Teknik pengumpulan data yang digunakan dalam penelitian ini adalah teknik dokumentasi, yaitu melakukan pengumpulan data dengan melakukan pencatatan yang besumber dari arsip, dokumen dan laporan-laporan yang dimuat oleh Kementerian Keuangan setiap tahunnya.

Teknik analisa data yang digunakan dalam penelitian ini adalah menggunakan analisis deskriptif. Adapun cara menganalisis data untuk mengetahui tingkat efektivitas adalah dengan membandingkan nilai realisasi pajak hotel dengan target pajak hotel yang telah ditetapkan Pemerintah Daerah Kota Medan kemudian nilainya disesuaikan dengan kriteria yang telah ditetapkan Kepmendagri No.690.900.327 tahun 1996 yaitu tidak efektif, kurang efektif, cukup efektif, efektif dan sangat efektif.

Efektifitas pajak hotel $=\frac{\text { Realisasi Pajak Hotel Kota Medan }}{\text { Target } \text { Pajak Hotel }} \times 100 \%$

Dan untuk mengetahui cara menganalisis kontribusi Pajak Hotel terhadap Pendapatan Asli Daerah (PAD) adalah dengan membandingkan nilai realisasi Pajak Hotel dengan realisasi Pendapatan Asli Daerah (PAD) Kota Medan dan menyesuaikan nilainya dengan kriteria yang telah ditetapkan Tim Litbang Depdagri Fisipol UGM tahun 1991 yaitu sangat kurang, kurang, cukup, sedang, baik, sangat baik.

Kontribusi pajak hotel $=\frac{\text { Realisasi Penerimaan } \text { Pajak } \text { Hotel }}{\text { Realisasi Pendapatan Asli Daerah }} \times 100 \%$ 


\section{HASIL DAN PEMBAHASAN}

Analisis efektivitas pajak Hotel adalah analisis yang mengukur kemampuan dalam merealisasikan Pajak hotel yang diperoleh Pemerintah Daerah dibandingkan dengan anggaran yang telah ditetapkan berdasarkan potensi daerah yang rill.

Tabel 3. Perkembangan Tingkat Efektivitas Pajak Hotel Tahun 2014-2018 Kota Medan

\begin{tabular}{llll}
\hline Tahun & Target Pajak Hotel & Realisasi Pajak Hotel & \% Efektivitas \\
\hline 2014 & 81.500 .000 .000 & 82.051 .748 .104 & 100.68 \\
2015 & 87.980 .801 .593 & 82.304 .995 .232 & 93,55 \\
2016 & 91.980 .801 .593 & 95.882 .427 .290 & 104,24 \\
2017 & 94.980 .301 .593 & 109.115 .442 .280 & 114,88 \\
2018 & 117.000 .000 .000 & 119.664 .695 .854 & 102,28 \\
\hline
\end{tabular}

Sumber: Data Penelitian, 2020

Berdasarkan Tabel 3, diketahui bahwa target penerimaan pajak hotel kota medan meningkat tiap tahunnya. Begitupun dengan realisasi penerimaan pajak hotel juga meningkat tiap tahun. Akan tetapi, maka tingkat efektivitas cenderung fluktuatif, naik turun setiap tahunnya. Berikut analisis tingkat efektivitas di setiap tahunnya berdasarkan perbandingan realisasi Pajak Hotel dengan target Pajak Hotel yang telah ditetapkan oleh Pemerintah Daerah Kota Medan sebagai berikut.

Tahun 2014, efektivitas pajak hotel bernilai 100,68\%, yang artinya nilai realisasi lebih tinggi dibandingkan nilai pajak hotel yang ditargetkan Pemerintah Daerah Kota Medan. Berdasarkan Kepmendagri No.690.900.327 tahun 1996, maka di tahun 2014, kategori efektivitas pajak hotel adalah sangat efektif.

Tahun 2015, efektivitas pajak hotel bernilai 93,55\% dimana target penerimaan pajak hotel yang ditetapkan Pemerintah Kota Medan lebih tinggi dibandingkan realisasi penerimaan pajak hotel. Berdasarkan Kepmendagri No.690.900.327 tahun 1996, maka di tahun 2015, kategori efektivitas pajak hotel efektif.

Tahun 2016 efektivitas pajak hotel bernilai 104,24\% dimana target penerimaan pajak hotel yang ditetapkan Pemerintah Kota Medan lebih tinggi dibandingkan realisasi penerimaan pajak hotel. Berdasarkan Kepmendagri No.690.900.327 tahun 1996, maka di tahun 2015, kategori efektivitas pajak hotel sangat efektif.

Tahun 2017 efektivitas pajak hotel bernilai 114,18 \% dimana target penerimaan pajak hotel yang ditetapkan Pemerintah Kota Medan lebih tinggi dibandingkan realisasi penerimaan pajak hotel. Berdasarkan Kepmendagri No.690.900.327 tahun 1996, maka di tahun 2015, kategori efektivitas pajak hotel sangat efektif.

Tahun 2018 efektivitas pajak hotel bernilai 102,28 \% dimana target penerimaan pajak hotel yang ditetapkan Pemerintah Kota Medan lebih tinggi dibandingkan realisasi penerimaan pajak hotel. Berdasarkan Kepmendagri No.690.900.327 tahun 1996, maka di tahun 2015, kategori efektivitas pajak hotel sangat efektif.

Pada tahun 2015, terjadi penurunan tingkat efektivitas pajak hotel dimana target penerimaan pajak hotel yang ditetapkan Pemerintah Kota Medan tidak 
tercapai. Menurut Peraturan Daerah Kota Medan Nomor 4 Tahun 2011, faktorfaktor yang menyebabkan belum tercapainya target pajak hotel sebagai berikut, Masih ada Wajib Pajak yang melaksanakan pembayaran tidak sesuai dengan nilai yang tercantum dalam Surat Ketetapan Pajak Daerah (SKPD). Masih ada Wajib Pajak yang menyampaikan Surat Pemberitahuan Pajak Daerah (SPTPD) tidak tepat waktu. Wajib Pajak belum sepenuhnya melaporkan dan menyetorkan pajak sesuai dengan ysng dikutip dari subjek pajak. Terdapat Wajib Pajak yang menutup usahanya tanpa pemberitahuan.

Analisis kontribusi Pajak Hotel suatu analisis yang digunakan untuk mengetahui seberapa besar kontribusi yang dapat disumbangkan dari penerimaan pajak hotel terhadap pendapatan asli daerah untuk mengetahui seberapa besar kontribusi yang dapat disumbangkan dari Pajak Hotel terhadap Pendapatan Asli Daerah

Tabel 4. Perkembangan Tingkat Kontribusi Pajak Hotel Kota Medan Tahun 2014-2018

\begin{tabular}{llll}
\hline Tahun & Realisasi Pajak Hotel & $\begin{array}{l}\text { Realisasi Pendapatan Asli } \\
\text { Daerah (PAD) }\end{array}$ & \% Kontribusi \\
\hline 2014 & 82.051 .748 .104 & 1.384 .246 .114 .729 & 5,93 \\
2015 & 82.304 .995 .232 & 1.413 .442 .053 .247 & 5,82 \\
2016 & 95.882 .427 .290 & 1.535 .309 .574 .015 & 6,24 \\
2017 & 109.115 .442 .280 & 1.739 .756 .922 .634 & 6,27 \\
2018 & 119.664 .695 .854 & 1.636 .204 .514 .684 & 7,31 \\
\hline
\end{tabular}

Sumber: Data Penelitian, 2020

Berdasarkan Tabel 4, diperoleh hasil bahwa realisasi Pajak Hotel Kota Medan terus meningkat setiap tahunnya. Akan tetapi, nilai realisasi Pendapatan Asli Daerah (PAD) Kota Medan cenderung fluktuatif, dimana pada tahun 20142017 nilainya meningkat, sedangkan di tahun 2018 mengalami penurunan. Nilai \% kontribusi meningkat setiap tahunnya. Berikut analisis kontribusi Pajak Hotel Kota Medan setiap tahunnya berdasarkan perbandingan realisasi Pajak Hotel dengan Pendapatan Asli Daerah (PAD) Kota Medan:

Di tahun 2014, nilai kontribusi Pajak Hotel sebesar 5,93\%. Berdasarkan kriteria Tim Litbang Depdagri Fisipol UGM tahun 1991, kontribusi Pajak Hotel terhadap Pendapatan Asli Daerah (PAD) Kota Medan sangat kurang.

Di tahun 2015, nilai kontribusi Pajak Hotel menurun hingga 5,82\%. Berdasarkan kriteriaTim Litbang Depdagri Fisipol UGM tahun 1991, kontribusi Pajak Hotel terhadap Pendapatan Asli Daerah (PAD) Kota Medan sangat kurang.

Di tahun 2016, nilai kontribusi Pajak Hotel menurun hingga 6,24\%. Berdasarkan kriteria Tim Litbang Depdagri Fisipol UGM tahun 1991, kontribusi Pajak Hotel terhadap Pendapatan Asli Daerah (PAD) Kota Medan sangat kurang.

Di tahun 2017, nilai kontribusi Pajak Hotel meningkat hingga 6,27\%, namun tidak lebih tinggi dibandingkan tahun 2015. Berdasarkan kriteria Tim Litbang Depdagri Fisipol UGM tahun 1991, kontribusi Pajak Hotel terhadap Pendapatan Asli Daerah (PAD) Kota Medan sangat kurang.

Di tahun 2018, nilai kontribusi Pajak Hotel menurun Kembali hingga 7,31\%. Berdasarkan kriteria Tim Litbang Depdagri Fisipol UGM tahun 1991, kontribusi Pajak Hotel terhadap Pendapatan Asli Daerah (PAD) Kota Medan sangat kurang. 
Meskipun nilai realisasi penerimaan pajak hotel meningkat dan \% kontribusi meningkat setiap tahunnya, akan tetapi, nilai realisasi Pendapatan Asli Daerah (PAD) yang menurun di tahun 2018 dimana sebelumnya di tahun 2014-2017 mengalami peningkatan. Peningkatan realisasi pajak hotel dan \% kontribusi pajak hotel terhadap Pendapatan Asli Daerah tidak begitu signifikan. Berdasarkan nilai persentase kontribusi di tahun 2014-1018, maka dapat dikatakan bahwa kontribusi Pajak Hotel Kota Medan terhadap Pendapatan Asli Daerah (PAD) masih sangat kurang. Hal ini bisa menjadi pertimbangan buat Pemerintah Kota Medan untuk memaksimalkan potensi pemungutan pajak hotel agar kontribusi Pajak Hotel terhadap Pendapatan Asli Daerah meningkat signifikan dan ini akan membuat pembangunan di daerah Kota Medan meningkat pesat.

\section{SIMPULAN}

Berdasarkan hasil dan pembahasan pada penelitian ini, maka dapat disimpulkan Efektivitas Pajak Hotel kota Medan cenderung fluktuatif setiap tahunnya. Pada tahun 2014-2018 efektivitas menurun dan berada di kriteria efektif hanya di 2015, selebihnya nilai efektivitas Pajak Hotel meningkat dan berada di kriteria sangat efektif. Kontribusi Pajak Hotel di kota Medan meningkat setiap tahunnya. Berbanding terbalik dengan efektivitas, kontribusi pajak Hotel terhadap Pendapatan Asli Daerah (PAD) Kota Medan berada di kriteria sangat kurang karena nilai kontribusi berada di angka di bawah $10 \%$.

Adapun keterbatasan dalam penelitian ini adalah nilai kontribusi Pajak Hotel terhadap Pendapatan Asli Daerah (PAD) Kota Medan bernilai dibawah $10 \%$ dan berada di kategori sangat kurang. Berdasarkan keterbatasan dalam penelitian, maka saran yang bisa diberikan adalah agar Pemerintah Daerah Kota Medan agar lebih memaksimalkan potensi penerimaan pajak hotel, dengan menagih utang pajak hotel bagi setiap wajib pajak sehingga penerimaan pajak hotel bisa meningkat signifan mengikut meningkatnya Pendapatan Asli Daerah.

Penulis menghaturkan terima kasih kepada Direktorat Riset dan Pengabdian Masyarakat, Direktorat Jenderal Penguatan Riset dan Pengembangan Kementerian Riset, Teknologi, dan Pendidikan Tinggi Republik Indonesia yang telah mendanai penelitian ini melalui skema Penelitian Dosen Pemula Tahun Anggaran 2020.

\section{REFERENSI}

Abdullah, I., \& Puspita, Y. A. (2016). Analisis Kontribusi Pajak Hotel Dalam Meningkatkan Pendapatan Asli Daerah (PAD) Kabupaten Deli Serdang. Jurnal Pajak Dan Bisnis, http://jurnal.umsu.ac.id/index.php/kumpulandosen/article/view/1850

Achsyariana, A. U. (2017). Kontribusi Wisata Alam Gunung Nona Terhadap Pendapatan Asli Daerah (PAD) Kabupaten Enrekang. Repository UIN Alauddin Makassar.

Bangun. (2019). Realisasi Pajak Daerah Kota Medan Tahun 2018 Capai 93,44 Persen. Diakses Pada 15 Agustus 2020. https://waspada.co.id/2019/01/realisasipajak-daerah-kota-medan-tahun-2018-capai-9344-persen/.\%60 
Betty, R. (2011). Analisis Potensi Pajak Hotel Terhadap Realisasi Penerimaan Pajak Hotel Di Kabupaten Gunungkidul. Fakultas Ekonomi Universitas Diponogoro.

Dani, H. (2006). Kamus Ilmiah Populer. Surabaya: Gita Media Press.

Falade O., Timothy A., Dubey, S. (2014). Managing Tourism as a source of Revenue and Foreign direct investment inflow in a developing Country: The Jordanian Experience. International Journal of Academic Research in Economics and Management Sciences. Vol 3 No.3

Halim, A. (2004). Akuntansi Keuangan Daerah Edisi Revisi. Jakarta: Salemba Empat.

Handoko P, S. (2013). Analisis Tingkat Efektivitas Pajak Daerah Sebagai Sumber Pendapatan Asli Daerah Kota Pontianak. Jurnal Ekonomi Daerah (JEDA) Vol 1 No. 1.

Hendrika, H. (2016). Analisis Pengelolaan Pendapatan Pajak Hotel, Restoran, Dan Reklame Dalam Menunjang Pendapatan Asli Daerah Kabupaten Landak. Equator Journal of Management and Entrepreneurship. Vol 4 No 3.

Keputusan Menteri dalam Negeri No. 690.900.327 Tahun 1996 tentang Kriteria Efektivitas.

Lestari, I. D., Manossoh, H., Afandi, D. (2018). Analisis Penerimaan Pajak Hotel Pada Kantor Badan Pengelola Pajak Dan Retribusi Daerah Kota Manado. Jurnal Riset Akuntansi Going Concern 13(2)

Muda, I, Ismail, M. \& Marhayanie. (2017), Impact Allocation Capital Expenditure on The Improvement of the Local Government Assets in North Sumatra and Effect on Local Revenue Sustainability. International Journal of Economic Perspectives. 11(2)

Naibaho, Y. (2019). Pansus Pembahasan LPj Nilai Pajak Hotel Dan Restoran Medan 2019 Tak Maksimal. https://waspada.id/headlines/pansus-pembahasanlpj-nilai-pajak-hotel-dan-restoran-medan-2019-tak-maksimal/

Norregard, J. (2013). Taxing Immovable Property Revenue Potential and Implementation Challenges. IMF Working Papers, 13(129). https:// doi.org/10.5089/9781484369050.001

Nazir, A., Basri, Y.M., Kamaliah \& Muda, I. (2017). Effectiveness of Potential Tax Region as the Real Local Revenue Sources in Riau Coastal Area. International Journal of Economic Research. 14, (12).

Octovido, I., Sudjana, N. \& Farah A. D. (2014). Analisis Efektivitas dan Kontribusi Pajak Daerah Sebagai Sumber Pendapatan Asli Daerah Kota Batu (Studi Pada Dinas Pendapatan Daerah Kota Batu Tahun 2009- 2013). Jurnal Administrasi Bisnis (JAB). 15 (1): 1-7

Peraturan Daerah (PERDA) Kota Medan No 4 tahun 2011 tentang Pajak Hotel

Saksono, P. B. (1984). Efektivitas Prinsip Organisasi. Jakarta: Galaxy Puspa Mega.

Sugiyono. (2016). Memahami Penelitian Kualitatif. Bandung: Alfabeta.

Sitompul, A., Syahnur, S. \& Ichsan, S. (2014). The Role Of Hotel And Restaurant Taxes And Its Effect On Banda Aceh's Local Own Source Revenue. Aceh International Journal of Social Sciences, Vol 3 No 1.

Taras, T., \& Artini, L. G. S. (2017). Analisis Pendapatan Asli Daerah (PAD) Dalam Upaya Pelaksanaan Otonomi Daerah di Kabupaten Badung Bali. E-Jurnal Manajemen, 
https://ojs.unud.ac.id/index.php/Manajemen/article/view/28206

Tarmizi, H.B., Daulay, M. \& Muda, I. (2016), The influence of population growth, economic growth and construction cost index on the local revenue of tax on acquisition of land and building after the implementation of law no. 28 of 2009. International Journal of Economic Research. 13(5)

Tim Litbang Depdagri Fisipol UGM Tahun 1991 tentang Kriteria Kontribusi.

Tonapa, Reny, H., Saerang, D., \& Mawikere, L. (2017). Analisis Potensi, Efektifitas Dan Kontribusi Pajak Hotel Terhadap Pendapatan Asli Daerah Kabupaten Tana Toraja. Jurnal Riset Akuntansi Going Concern, 12(1). https:// doi.org/oi.org/10.32400/gc.12.01.17145.2017

Undang-Undang Nomor 33 Tahun 2004 tentang Perimbangan Keuangan Antara Pusat dan Daerah

Wirawati, N. G. P., \& Putra, I. N. W. A. (2019). Analysis Of Factors That Influence The Compliance Of Tax And Restaurant Taxes In Tabanan Regency Of Bali, Indonesia. RJOAS: Russian Journal of Agricultural and Socio-Economic Sciences, 86(2) 